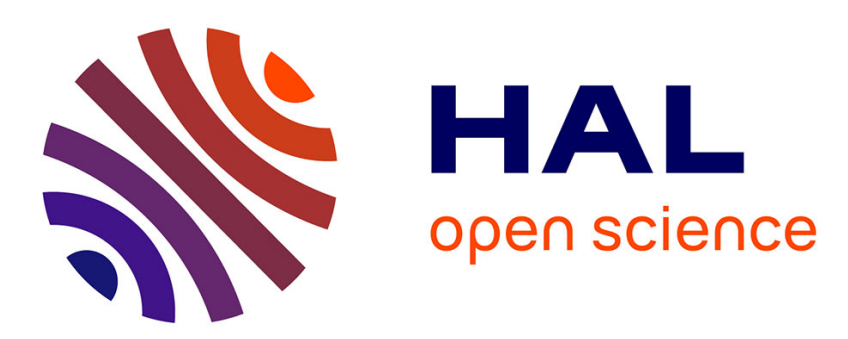

\title{
Atomic force microscopy images suggest aggregation mechanism in cerato-platanin
}

F. Sbrana, L. Bongini, G. Cappugi, D. Fanelli, Alessio Guarino, L. Pazzagli, A. Scala, M. Vassalli, C. Zoppi, B. Tiribilli

\section{- To cite this version:}

F. Sbrana, L. Bongini, G. Cappugi, D. Fanelli, Alessio Guarino, et al.. Atomic force microscopy images suggest aggregation mechanism in cerato-platanin. European Biophysics Journal, 2007, 36 (7), pp.727-732. 10.1007/s00249-007-0159-x . hal-02059668

\section{HAL Id: hal-02059668 https://hal.science/hal-02059668}

Submitted on 30 Apr 2019

HAL is a multi-disciplinary open access archive for the deposit and dissemination of scientific research documents, whether they are published or not. The documents may come from teaching and research institutions in France or abroad, or from public or private research centers.
L'archive ouverte pluridisciplinaire HAL, est destinée au dépôt et à la diffusion de documents scientifiques de niveau recherche, publiés ou non, émanant des établissements d'enseignement et de recherche français ou étrangers, des laboratoires publics ou privés. 


\title{
Atomic force microscopy images suggest aggregation mechanism in cerato-platanin
}

\author{
F. Sbrana $\cdot$ L. Bongini $\cdot$ G. Cappugi $\cdot$ D. Fanelli $\cdot$ \\ A. Guarino $\cdot$ L. Pazzagli $\cdot$ A. Scala $\cdot$ M. Vassalli $\cdot$ \\ C. Zoppi · B. Tiribilli
}

Received: 21 December 2006/Revised: 16 March 2007/Accepted: 20 March 2007

(C) EBSA 2007

\begin{abstract}
Cerato-platanin (CP), the first member of the “cerato-platanin family", is a moderately hydrophobic protein produced by Ceratocystis fimbriata, the causal agent of a severe plant disease called "canker stain". The protein is localized in the cell wall of the fungus and it seems to be involved in the host-plane interaction and induces both cell necrosis and phytoalexin synthesis (one of the first plant defence-related events). Recently, it has been determined that $\mathrm{CP}$, like other fungal surface protein, is able to self assemble in vitro. In this paper we characterize the aggregates of $\mathrm{CP}$ by Atomic Force Microscopy (AFM) images. We observe that CP tends to form early annular-shaped oligomers that seem to constitute the fundamental bricks of a hierarchical aggregation process, eventually resulting in large macrofibrillar assemblies. A simple model, based on the hypothesis that the aggregation is energetically favourable when the exposed surface is reduced, is compatible
\end{abstract}

Proceedings of the XVIII Congress of the Italian Society of Pure and Applied Biophysics (SIBPA), Palermo, Sicily, September 2006.

F. Sbrana · D. Fanelli · M. Vassalli · B. Tiribilli

C.S.D.C, Dip. Fisica, Università di Firenze, Via Sansone, 1,

50019 Sesto Fiorentino, Firenze, Italy

L. Bongini

Dip. Fisica, Università di Firenze, Via Sansone, 1,

50019 Sesto Fiorentino, Firenze, Italy

G. Cappugi · L. Pazzagli · C. Zoppi

Dip. di Scienze Biochimiche, Università di Firenze,

Viale Morgagni, 50, 50134 Sesto Fiorentino, Firenze, Italy

D. Fanelli

Theoretical Physics, School of Physics and Astronomy,

University of Manchester, Manchester,

M13, 9PL Manchester, UK with the measured aggregates' shape and size. The proposed model can help to understand the mechanism by which $\mathrm{CP}$ and many other fungal surface proteins exert their effects.

Keywords Protein aggregation · Cerato-platanin · AFM

\section{Introduction}

Cerato-platanin (CP) is produced by the ascomycete fungus Ceratocystis fimbriata, which is the causative agent of cancer stain, a severe disease with incidence in a great number of plants, e.g. Platanus acerifolia, Theobroma cacao, Coffea arabic. The secreted CP is a 120 amino acid protein, moderately hydrophobic and turned out to be the first member of the "cerato-platanin

A. Guarino

Université de la Polynesie Francaise, Tahiti, French Polynesia

A. Scala

Dip. di Biotecnologie Agrarie, Sezione di Patologia Vegetale, Università di Firenze, Via della Lastruccia 10,

50019 Sesto Fiorentino, Italy

M. Vassalli · B. Tiribilli ( $\square)$

ISC, CNR, Istituto Sistemi Complessi, Via Madonna del Piano,

Sesto Fiorentino, Firenze 50019, Italy

e-mail: bruno.tiribilli@isc.cnr.it

D. Fanelli $\cdot$ M. Vassalli

I.N.F.N, Sezione di Firenze, Via Sansone, 1,

50019 Sesto Fiorentino, Firenze, Italy 
family" that includes seven other proteins secreted from Ascomycetes (Pazzagli et al. 1999). Some of these proteins seem to be involved in various stages of the host-fungus interaction: for example, the product of the snodprotl gene from $P$. nodorum is produced during infection of wheat leaves; the allergen Asp f13 causes an allergic reaction in humans; the CS antigen is produced by $C$. immitis, the causative agent of a human respiratory disease; and the sp1 protein by L. maculans, the blackleg pathogen of Brassica napus (Pazzagli et al. 2006; Djonović et al. 2006). Moreover, CP shares some structural and functional characteristics with other fungal proteins called hydrophobins: it is moderately hydrophobic, its secondary structure prediction indicates the presence of mainly $\beta$-sheet, and it is an important component of the cell wall of hyphae, ameroconidia, and ascospores (Boddi et al. 2004; Scala et al. 2004).

Hydrophobins are secreted fungal proteins which have a wide range of functions in fungal growth and development that are all apparently related to their surface activity: these proteins self-assemble in an insoluble amphipathic membrane at hydrophobic/hydrophilic interfaces acting as biosurfactant (Askolin et al. 2006; Wosten 2001; Linder et al. 2005; Kwan et al. 2006). Hydrophobins are characterized by a low sequence similarity and they can be divided into Class I and Class II on the basis of their hydropathy. Class I hydrophobins are found to form a "rodlet coating" that, at molecular level, fulfil many of the criteria for amyloid assemblies found in human neurodegenerative diseases (Mackay et al. 2001; Stroud et al. 2003). Instead, class II hydrophobins form tetrameric aggregates found in aqueous solutions of HFBII (Hakanpaa et al. 2004). Recent in vitro investigations clarified the ability of $\mathrm{CP}$ to self-assemble (Carresi et al. 2006).

In this paper we studied these aggregates by AFM, a powerful technique that enables one to resolve the supramolecular organization of the amyloid and amyloid-like aggregates (Mackay et al. 2001; Chamberlain et al. 2000; Soldi et al. 2005).

\section{Experimental (materials and methods)}

\section{Chemicals and buffers}

All chemicals were purchased from Sigma-Aldrich ( $\mathrm{St}$ Louis, MO, USA); reagents and kits for the Pichia expression kit, restriction enzymes, T4-DNA ligase and Taq DNA polymerase were purchased from Invitrogen (San Diego, CA, USA). The semi-preparative ReversePhase (RP) HPLC column $(\mathrm{C} 4,5 \mu \mathrm{m}, 250 \times 10 \mathrm{~mm})$ was from Vydac (Grace, Columbia, MD, USA).
Expression, purification and aggregation of cerato-platanin

CP gene (Pazzagli et al. 2006) was cloned in a pPIC9 vector of the methyltrophic yeast Pichia pastoris that enables the extracellular expression of the recombinant proteins. Protein expression and purification was carried out as previously described (Carresi et al. 2006).

TFE is a reagent commonly used to induce in vitro aggregation of amyloid proteins (Calamai et al. 2005; Soldi et al. 2005). Aggregation of CP was carried out incubating $0.54 \mathrm{mM}$ CP in 30\% TFE in water and in 30\% TFE in 0.1 M Na-acetate buffer $\mathrm{pH} 4.3$.

Thioflavine (ThT) (LeVine 1993; Naiki et al. 1989) fluorescence and circular dichroism (CD) (Chiti et al. 1999) were used to test aggregation. Briefly, after 5, 20 and 35 days of incubation, $5 \mu \mathrm{l}$ of the $\mathrm{CP}$ solution was added to $500 \mu \mathrm{l}$ of $6.4 \mu \mathrm{M}$ ThT in $50 \mathrm{mM}$ glycine- $\mathrm{NaOH}$ buffer $\mathrm{pH}$ 8.5; fluorescence emission was measured on a PerkinElmer LS-55 spectrofluorimeter. CD spectra were acquired on a Jasco J-810 Spectropolarimeter at $20^{\circ} \mathrm{C}$ using $6 \mu \mathrm{l}$ of the incubated $\mathrm{CP}$ solution dissolved in $240 \mu \mathrm{l}$ of water. Fluorescence measurements at 5,20 and 35 days show increasing values of $0.65 \pm 0.14,5.40 \pm 1.70$ and $51.23 \pm$ 8.70 (Intensity Units) respectively and point out that aggregation had occurred. The CD results indicate that the protein was misfolded from the beginning of the incubation. These samples were dried and stored at $-80^{\circ} \mathrm{C}$ until to use them in AFM imaging.

\section{Atomic force microscopy}

Atomic force microscopy (AFM) analysis of the CP was performed at different times (5,20 and 35 days) during the aggregation process. The sample preparation $2 \mu \mathrm{l}$ of $\mathrm{CP}$ were laid onto a freshly cleaved mica disc, rinsed with a few drops of distilled water and dried with a soft nitrogen blow. Solutions of suspended aggregates were gently agitated to ensure that the drop was representative of the whole sample.

AFM experiments were performed in air, in non-contact mode, using a PicoSPM microscope equipped with AACMode controller (Molecular Imaging, Phoenix, AZ, USA). The probes characteristics are model NSG-01 (NT-MDT Co., Moscow, Russia) with $150 \mathrm{kHz}$ typical resonance frequency. Scanner calibration was periodically checked by means of a reference grid (TGZ02 by MikroMash, Tallin, Estonia) with known pitch, $3 \mu \mathrm{m}$, and step height, $100 \mathrm{~nm}$.

Image processing

Images recorded from AFM were processed with automatic recognition algorithms in order to identify and measure 
single features, as aggregates or small (annular shaped) oligomers. Using an open source software (Image J, http:// www.rsb.info.nih.gov/ij) AFM images were first treated to eliminate the background and than thresholded (binarized).

The average (external) diameter of the oligomers is estimated by tracing the location of the maximum of the particle size distribution $P(r)$, as obtained from standard granulometry routine.

The protein aggregates were fitted to oval profiles to find the ratio $R$ between minor and major axis (circularity algorithm).

\section{Results and discussion}

Proteins have a generic tendency to convert from their soluble states into insoluble well-organised aggregates known as amyloid or amyloid-like fibrils. This tendency is reported in different medical contexts and often results in pathology, including Alzheimer, Parkinson disease and type II diabetes (Chiti and Dobson 2006). It is therefore of paramount importance to elucidate the pathway by which proteins assemble into ordered aggregates eventually responsible for cell dysfunction. Moreover, aggregation seems to be a common mechanism by which many proteins exert their effects. The fungal proteins called hydrophobins are involved in developmental and host-interaction mechanisms that can be related to their ability to self assemble into amyloid-like structure (Wosten 2001; Linder et al. 2005; Kwan et al. 2006). Also cerato-platanin, the first member of the cerato-platanin family is able to selfassemble in solution, but the aggregates' morphology differs from that relative to both amyloid and hydrophobins aggregates. We shall here suggest a dynamic mechanism that supposedly governs the process of formation of the aggregates. First, we will develop a highly speculative model and then analyze the images acquired with the AFM to provide a quantitative support to the proposed interpretative framework.

Data obtained from Tht fluorescence and Circular Dichroism spectra suggest that $\mathrm{CP}$ undergoes a misfolding before the aggregation is entrained. AFM measurements performed at different incubation's times enabled us to visualize the various steps of $\mathrm{CP}$ self-assembly process: after a few days of incubation, small structures are found already and after 20 days large aggregates develop, the latter being characterized by a rich and diverse morphology (see Figs. 1, 2). Such aggregates increase in number and dimension as time progresses. Nevertheless, they are always found to be surrounded by a layer of smaller objects, identical to the ones observed in the early stage of incubation (see Fig. 2b).

Let us turn to analyzing Fig. 1a, where a typical AFM image of $\mathrm{CP}$ aggregates is presented. Branched structures are clearly displayed, each large agglomerate being characterized by a disordered assembly of protruding segments. Their characteristic size falls in the range of hundreds of nanometers, as testified by a visual comparison with the reference scale enclosed in Fig 1a. Enlarging the figure (see Fig. 1b), one can resolve the details of the fibrillar structure and appreciate its longitudinal roughness. It can be hypothesized that these in-homogeneities are the relic of a complex hierarchical aggregation process, the subsequent merging of constitutive blocks giving rise to the observed corrugated profile. Interestingly, large aggregates are immersed in a dense carpet of smaller oligomers (see Fig. 2a), presenting a characteristic doughnut-like (or annular) shape (see Fig. 2b). The diameter of the inner hole is sensibly smaller than the external one (a factor 5) and thus comparable with AFM resolution limit. These elements are almost flat, the height being smaller than the diameter (see profile in Fig. 2c). One can hence imagine that such annular objects are the fundamental bricks of the underlying aggregation scheme. Moreover, we assume that, due to the
Fig. 1 a AFM topography of cerato-platanin aggregates (sample dilution 1:4) on freshly cleaved mica substrate.

b Branched structures of hundreds of nanometers in length are often present. They appear to be constituted by protruding segments whose height is of about $50-60 \mathrm{~nm}$. c Profile of section outlined in (b)
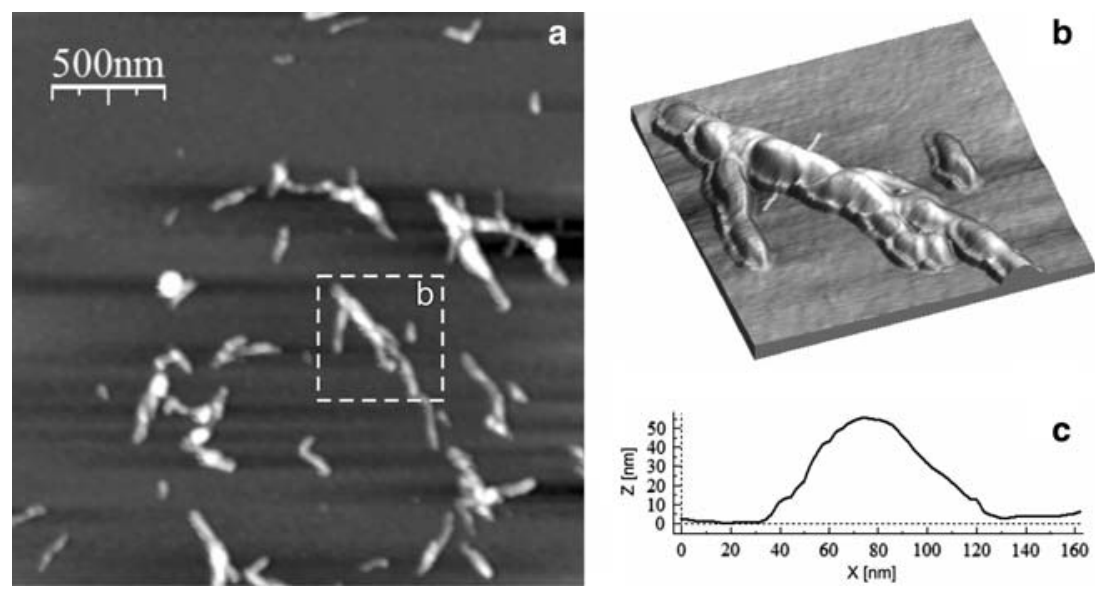
Fig. 2 a AFM topography of cerato-platanin aggregates (sample dilution 1:4) on freshly cleaved mica substrate.

Together with large aggregates, a carpet of small (annular shaped) elements is clearly displayed. b Zoom of image (a) showing doughnut-like (annular) elements with typical height of about $6-8 \mathrm{~nm}$ c profile of section outlined in (b)
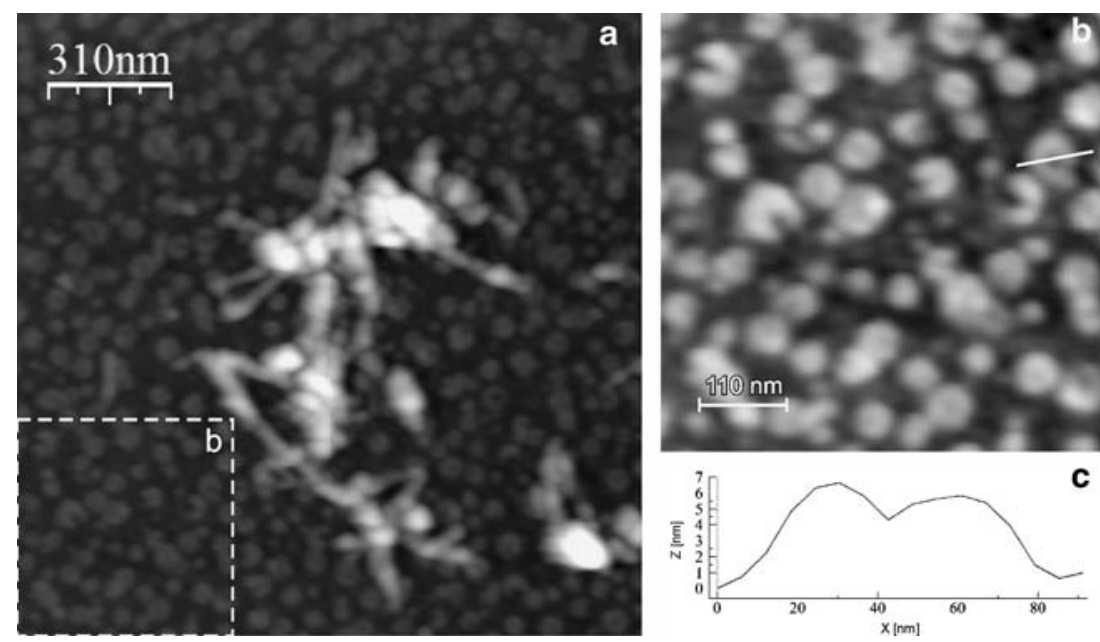

hydrophobic nature of the specimen under scrutiny, it is energetically convenient to minimize the surface exposed to the contact with water and consequently suppose the dynamics to be driven by such mechanism. Neglecting the small contribution, of the inner hole to the external surface, we shall here assimilate the annular oligomers to homogeneous cylinders. The surface of the cylinder base reads

$A_{S}=\pi(D / 2)^{2}$.

Based on the above reasoning, and since the oligomers are longitudinally compressed, two nearby structures will preferentially superpose the adjacent bases thus shielding the largest possible portion of their surface $\left(A_{\mathrm{S}}\right)$ to the interaction with the surrounding solution. As the stacking reaction proceeds forward, the lateral surface $A_{1}$ increases, while the aggregate maintains a cylindrical structure, the surface of the associated base still being $A_{\mathrm{S}}$. After a number of successive encounters, it will become equally convenient to establish a connection between homologous assemblies through their lateral surfaces. The lateral interaction shields a fraction of the lateral surface that can be quantified invoking the following argument: the optimal packing of cylindrical units is obtained by a hexagons symmetry, where each cylindrical element shares a portion $\alpha=1 / 6$ of its lateral surface. ${ }^{1}$ The side-to-side attachment should therefore manifest when

$2 A_{\mathrm{S}}=2 \pi \alpha D H_{\mathrm{c}}$

where $H_{\mathrm{c}}$ identifies the critical height threshold, resulting from a number of consecutive base-to base merging. Expressions (1) and (2) finally yields:

\footnotetext{
${ }^{1}$ The choice $\alpha=1 / 6$ is consistent with the assumption built in the model. The hexagonal lattice (also termed bees' honeycomb) optimizes circles packing, and hence minimizes the unshielded surface associated to the central (circular) element (Williams 1979).
}

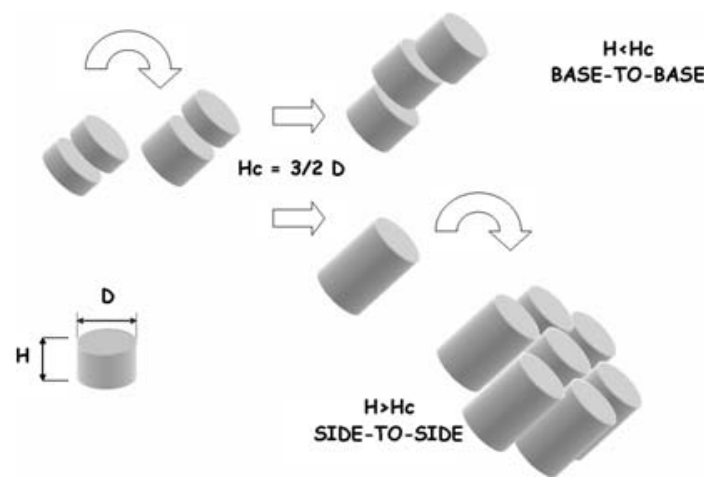

Fig. 3 The cartoon exemplifies the model of hierarchical aggregation proposed in the text. The reaction proceeds by assembling small cylindrical units, accordingly to the base-to-base scenario, until the height reaches the critical value, $H_{\mathrm{c}}$, above which the side-to-side attachment is energetically favoured

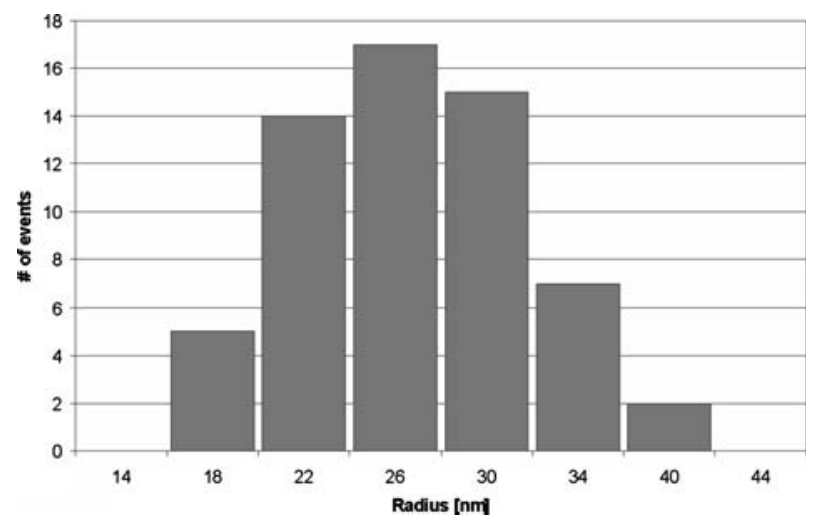

Fig. 4 Statistical distribution of radius of small disks from AFM data (Fig. 2). The peak value is $26 \mathrm{~nm}$

$D=2 / 3 H_{\mathrm{c}}$

The scheme of the interaction is depicted in figure (Fig. 3). Let us now turn to analyze the AFM images with 
Fig. 5 a AFM image of aggregated $\mathrm{CP}$, sample not diluted. Laterally adjacent ovals are clearly evident in various regions; dotted squares outline some of them. b The figure shows the distribution of the minor/major axis ratio $R$ of the identified oval features. The maximum is in correspondence of the predicted value, expected for $R=D / H_{\mathrm{c}}=2 / 3$
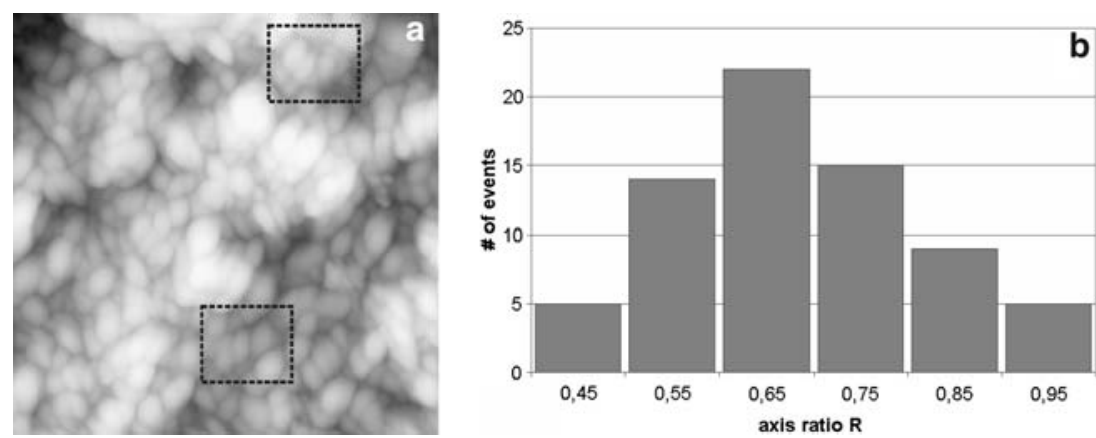

the aim of testing the correctness of our conclusions. First, we measured the (external) radius for each annular oligomer selected from Fig. 2. These data are combined to reconstruct the probability distribution function reported in Fig. 4: a mean value of about $26 \mathrm{~nm}$ is found. Focus now is on Fig. 5: This snapshot refers to an intermediate stage of the evolution, which precedes the formation of the large filamented structures of Fig. 1. Elongated (oval shaped) units are visible and are shown to adhere in adjacent pairs equally following the side-to-side and base-to-base options. The oval elements are almost identical in size and can be fitted to ellipsoids, whose major and minor axes are respectively labeled $A$ and $B$. $A$ direct measure shows that $B \approx D$, thus confirming that the oval structures are compatible with the paradigm of successive base-to-base piling of annular blocks. However, since lateral and longitudinal merging are both manifested in fig $5 \mathrm{a}$, we expect the ratio $R=B / A \approx D / A$ to be peaked in $2 / 3$, as prescribed by formula (3). The histogram of $R$ is calculated upon inspection of Fig. 5a and reported in Fig. 5b. A pronounced maximum is indeed found where predicted by the theory. These findings provide an aposteriori experimental support to the validity of the proposed mechanism of aggregation, showing that hydrophobic forces play a key role in the aggregation process, the latter being supposedly responsible for successive assembly of small elements into larger complex structures.

In conclusion, it is worth emphasizing that cerato-platanin aggregates obtained by incubation of $0.54 \mathrm{mM} \mathrm{CP}$ in $30 \%$ TFE share some peculiar features with the amyloid fibrils and with aggregates formed by hydrophobins, even though a direct analogy cannot be formally established. Moreover, the proteins belonging to the cerato-platanin family presents a noticeable high-sequence similarity, unusual among the other fungal protein families, that can be indicative of a similar hydrophobic surface exposition in solution. Based on the above we can hence hypothesize that a mechanism of aggregation similar to the one debated here holds in other contexts, including others representative of the wide CP-like proteins family. In this perspective, the proposed model can constitute an important leap forward in clarifying the essential role of the aggregates in the fungalplant interaction and further contribute to shed new light onto the crucial mechanism by which other proteins of the "CP family" interact with their hosts.

\section{References}

Askolin S, Linder M, Scholtmeijer K, Tenkanen M, Penttilä M, de Vocht ML, Wösten HAB (2006) Interaction and comparison of a class I hydrophobin from Schizophyllum commune and class II hydrophobins from Trichoderma reesei. Biomacromolecules 7:1295-1301

Boddi S, Comparini C, Calamassi R, Pazzagli L, Cappugi G, Scala A (2004) Cerato-platanin protein is located in the cell walls of ascospores, conidia and hyphae of Ceratocystis fimbriata $f$. sp. Platani. FEMS Microbiol Lett 233:341-346

Carresi L, Pantera B, Zoppi C, Cappugi G, Oliveira AL, Pertinhez TA, Spisni A, Scala A Pazzagli L (2006) Cerato-platanin, a phytotoxic protein from Ceratocystis fimbriata: expression in Pichia pastoris, purification and characterization. Protein Expr Purif 49:159-167

Chamberlain AK, MacPhee CE, Zurdo J, Morozova-Roche LA, Hill HAO, Dobson CM, Davis J (2000) Ultrastructural organization of amyloid fibrils by atomic force microscopy. Biophys $\mathrm{J}$ 79:3282-3293

Chiti F, Webster P, Taddei N, Clark A, Stefani M, Ramponi G, Dobson CM (1999) Designing conditions for in vitro formation of amyloid protofilaments and fibrils 1999. Proc Natl Acad Sci USA 96:3590-3594

Chiti F, Dobson CM (2006) Protein misfolding, functional amyloid, and human disease. Annu Rev Biochem 75:333-336

Djonović S, Pozo MJ, Dangott LJ, Howell CR, Kenerley CM (2006) $\mathrm{Sm} 1$, a proteinaceous elicitor secreted by the biocontrol fungus Trichoderma virens induces plant defense responses and systemic resistance. Mol Plant Microbe Interact 19:838-853

Hakanpaa J, Paananen A, Askolin S, Nakari-Setala T, Parkkinen T, Penttila M, Linder MB, Rouvinen J (2004) Atomic resolution structure of the HFBII hydrophobin, a self-assembling amphiphile. J Biol Chem 279:534-539

Kwan AH, Winefield RD, Sunde M, Matthews JM, Haverkamp RG, Templeton MD, Mackay JP (2006) Structural basis for rodlet assembly in fungal hydrophobins. Proc Natl Acad Sci USA 103:3621-3626

LeVine H (1993) Thioflavine T interaction with synthetic Alzheimer's disease b-amyloid peptides: detection of amyloid aggregation in solution. Protein Sci 2:404-410

Linder MB, Szilvay GR, Nakari-SetäläT, Penttila ME (2005) Hydrophobins: the protein-amphiphiles of filamentous fungi. FEMS Microbiol Rev 29:877-896 
Mackay JP, Matthews JM, Winefield RD, Mackay LG, Haverkamp RG, Templeton MD (2001) The hydrophobin EAS is largely unstructured in solution and functions by forming amyloid- like structures. Structure (Camb) 9:83-91

Naiki H, Higuchi K, Hosokawa M, Takeda T (1989) Fluorometric determination of amyloid fibrils in vitro using the fluorescent dye, Thioflavine T1 Anal Biochem 177:244-249

Pazzagli L, Cappugi G, Manao G, Camici G, Santini A, Scala A (1999) Purification, characterization, and amino acid sequence of cerato-platanin, a new phytotoxic protein from Ceratocystis fimbriata f. sp. Platani. J Biol Chem 274:24959-24964

Pazzagli L, Pantera B, Carresi L, Pertinhez TA, Spisni A, Tegli S, Zoppi C, Scala A, Cappugi G (2006) Cerato-platanin, the first member of a new fungal protein family: cloning, expression and characterization. Cell Biochem Biophys 44:512-521

Scala A, Pazzagli L, Comparini C, Santini A, Tegli S, Cappugi G (2004) Cerato-platanin an early-produced protein by Ceratocys- tis fimbriata f.sp. platani elicits phytoalexin synthesis in host and non-host plants. J Plant Pathol 86:23-29

Soldi G, Bemporad F, Torrassa S, Relini A, Ramazzotti M, Taddei N, Chiti F (2005) Amyloid formation of a protein in the absence of initial unfolding and destabilization of the native state. Biophys $\mathbf{J}$ 89:4234-4244

Stroud PA, Goodwin JS, Butko P, Cannon GC, McCormick CL (2003) Experimental evidence for multiple assembled states of Sc3 from Schizophyllum commune. Biomacromolecules 4:956967

Williams R (1979) Circle packings, plane tessellations, and networks. In: The Geometrical foundation of natural structure: a source book of design. Dover, New York, pp 34-47

Wösten HAB (2001) Hydrophobins: multipurpose proteins. Annu Rev Microbiol 55:625-46 